\title{
Effect of carbamazepine and valproic acid monotherapy on thyroid function tests in epileptic patients
}

\author{
Ashraf H. Ahmed, Imad A. Thanoon
}

Department of Pharmacology, College of Medicine, University of Mosul

(Ann. Coll. Med. Mosul 2006; 32(1\&2):57-62)

Received: $17^{\text {th }}$ May, 2006; Accepted: $29^{\text {th }}$ Nov, 2006

\begin{abstract}
Objectives: This study was conducted to assess the effect of carbamazepine (CBZ) and sodium valproate (VPA), as a monotherapy in epileptic patients, on thyroid function tests as assessed by serum total triiodothyronine $\left(\mathrm{TT}_{3}\right)$, total thyroxine $\left(\mathrm{TT}_{4}\right)$ and thyroid stimulating hormone(TSH).

Subjects and methods: Sixty three epileptic patients using monotherapy were included in the study. These included 44 patients using CBZ and 19 using VPA. A control group of 47 apparently healthy individuals were also included in the study for comparison. Measurement of TSH, $\mathrm{TT}_{3}$ and $\mathrm{TT}_{4}$ was done using Gamma counter.

Results: The results of this study revealed that patients on $\mathrm{CBZ}$ showed significantly decreased mean level of $\mathrm{TT}_{4}$ in comparison with the control group $(P<0.01)$, while mean $\mathrm{TT}_{3}$ and $\mathrm{TSH}$ levels showed statistically insignificant differences from the control group $(P>0.05)$. In the VPA group, mean $\mathrm{TT}_{3}, \mathrm{TT}_{4}$ and $\mathrm{TSH}$ values showed insignificant differences from the control group $(P>0.05)$.

Conclusion: Unlike VPA, CBZ significantly decreases level of $T T_{4}$ without affecting $T T_{3}$ and TSH levels.
\end{abstract}

Keywords: Carbamazepine, sodium valproate, thyroid function tests.

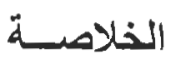

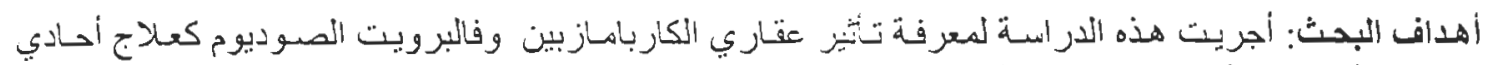

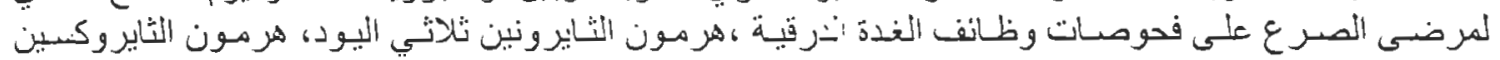

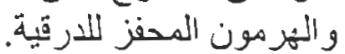

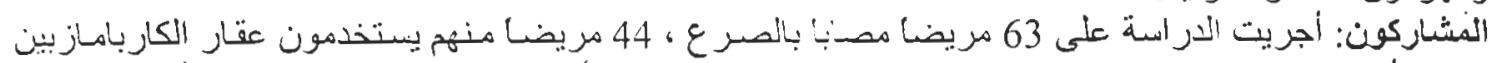

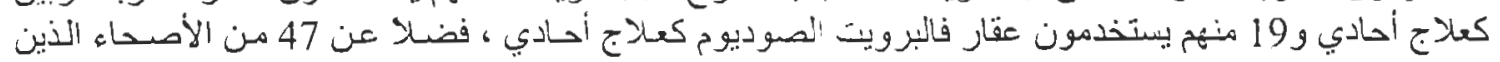

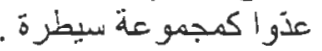
تم قيانس منتويات هرمون الثابرونين ثناتي اليود ودمرمون الثايروكيدين و النهورمون المحفز للارقية لأفر اد عينة

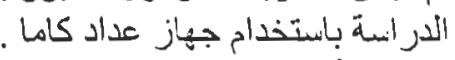

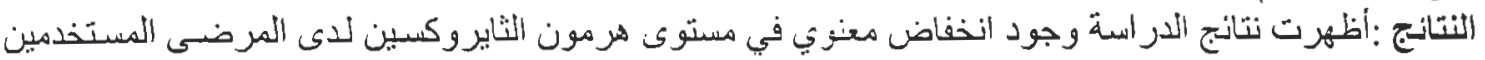

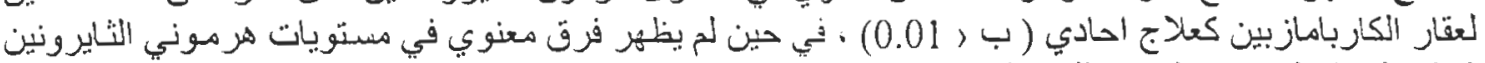

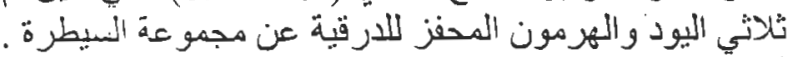

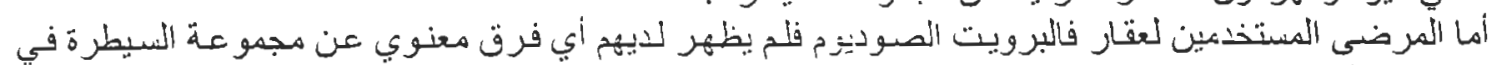

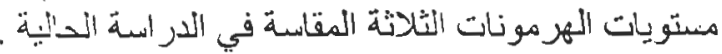

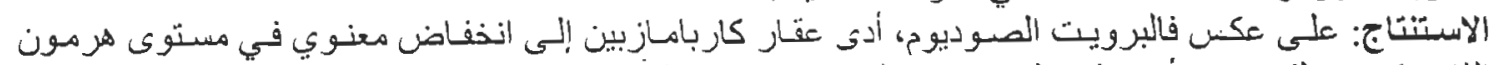

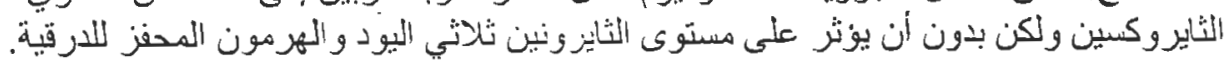

$\mathrm{T}$

hyroid diseases are usually presented as a spectrum of clinical and metabolic features of varying severity. Although primary diseases of the thyroid gland are the most common, secondary disorders due to hypothalamicpituitary insufficiency can also give rise to dysfunctional states $^{(1)}$. Many other factors, both exogenous and endogenous, may affect the thyroid function ${ }^{(2.3)}$. These include the pathways of thyroid hormone biosynthesis, secretion, transport in the circulation, and metabolism which offer numerous targets for drug interaction ${ }^{(4)}$.

Euthyroid hypothyroxinaemia, describes a situation in which total or free thyroxine 
concentrations are low but without evidence of thyroid dysfunction, usually with a normal TSH, This may be associated with medication or non-thyroidal illnesses like liver or renal disease, heart failure, and post-surgery $^{(5)}$.

Carbamazepine (CBZ) is one of the most important antiepileptic drugs. It is an iminostilbene of tricyclic structure related to imipramine and other antidepressants ${ }^{(6)}$. Thyroid function tests may be abnormal in patients receiving $\mathrm{CBZ}$ therapy ${ }^{(7)}$. Numerous studies have shown that serum thyroid hormones concentrations are decreased following treatment with CBZ but in the absence of clinical signs of hypothyroidism $^{(8,9,10)}$. Valproate (VPA) medication in women with epilepsy is associated with certain metabolic and endocrine changes ${ }^{(11)}$. It may also affect steroid hormone metabolism in men with epilepsy ${ }^{(12)}$. However, reports on serum thyroid hormone levels in patients with epilepsy treated with VPA have been conflicting $^{(8,9,10)}$.

The aim of the current study is to assess the effects of CBZ and VPA, as monotherapy in epileptic patients, on serum total $\mathrm{T}_{3}\left(\mathrm{TT}_{3}\right)$, total $\mathrm{T}_{4}\left(\mathrm{TT}_{4}\right)$ and $\mathrm{TSH}$.

\section{Subjects and methods}

This study was carried out during the period, from $15^{\text {th }}$ Sept 2003 to $30^{\text {th }}$ May 2004. Patients were received and interviewed with the main exclusion criteria from the study as follows:

1. Patients receiving other anti-epileptic drug or poly therapy.

2. Duration of therapy of less than 6 months

3. Signs or symptoms of liver disease, renal disease, thyroid disease or diabetes mellitus.

4. Abnormal neurological examination

5. Long term use of any other drug.
Group 1: This group included 44 epilep patients on CBZ as a monotherapy for period ranging from 6 months- 14 yea (mean \pm SD $4.82 \pm 3.19$ years), we included in this study. They were 18 male and 26 females with age of $28.43 \pm 8$. years, and ranging of $6-50$ years. The mea CBZ daily dose was $559.09 \pm 138.69 \mathrm{mg}$ , and range of $400-800 \mathrm{mg} / \mathrm{d}$.

Group 2: This group included 19 patient who were treated with sodium VPA as monotherapy for a period ranging from months -12 years $(4.58 \pm 3.32$ year). The were 9 males and 10 females with mea age of $28.88 \pm 7.37$ years, and range of 1 40 years. The sodium VPA daily dose we $588.88 \pm 127.82 \mathrm{mg} / \mathrm{d}$, ranged from 40 $800 \mathrm{mg} / \mathrm{d}$

Group 3: This group included apparently healthy persons, who had chronic disease and did not receive ar drugs during the last two weeks. They we 22 males and 25 females with mean age $28.31 \pm 8.54$ year, and range of $14-4$ years.

From all patients and controls, about 5 of venous blood samples were collected plain tubes. Collection was done early the morning in the fasting state. Thyro function tests which include serum $\mathrm{TT}_{3}, \mathrm{~T}^{-}$ and $\mathrm{TSH}$ concentrations were measured Radioimmunoassay using kits purchase from Immunotech (France)

The statistical methods were used for tr analysis of data that includes determinatic of the mean, standard deviation (SD) ar standard error (SE), unpaired student t-tes unpaired Z-test, analysis of varianc (ANOVA) and Pearson correlatic coefficient. The differences betwee observations were considered significant $P \leq 0.05^{(13)}$ The data are presented mean \pm SD.

Table (1): Comparison of thyroid function tests between control and carbamazepine (CB. treated groups.

\begin{tabular}{|l|c|c|c|c|}
\hline \multirow{2}{*}{ Parameter } & \multicolumn{2}{|c|}{ Mean \pm SD } & z-value & p-value \\
\cline { 2 - 5 } & Control $(\mathrm{n}=47)$ & Patients on CBZ $(\mathrm{n}=44)$ & 0.02 & $>0.05$ \\
\hline$\Pi_{3}(\mathrm{nmol} / \mathrm{L})$ & $1.84 \pm 0.44$ & $1.86 \pm 0.52$ & 2.89 & $<0.01^{\star}$ \\
\hline$\Pi_{4}(\mathrm{nmol} / \mathrm{L})$ & $119.22 \pm 18.07$ & $101.49 \pm 36.87$ & 0.004 & $>0.05$ \\
\hline $\mathrm{TSH}(\mathrm{mlU} / \mathrm{L})$ & $2.24 \pm 0.76$ & $2.52 \pm 1.42$ & \\
\hline
\end{tabular}

* Significant difference $(p<0.01)$

Table (2): Effect of carbamazepine dosage on thyroid function tests.

\begin{tabular}{|c|c|c|c|}
\hline \multirow{2}{*}{ Dosage (mg/day) } & \multicolumn{3}{|c|}{ Mean \pm SE } \\
\hline & $\pi_{3}(\mathrm{nmo} / \mathrm{L})$ & $\pi_{4}(\mathrm{nmol} / \mathrm{L})$ & $\mathrm{TSH}(\mathrm{mlU} / \mathrm{L})$ \\
\hline $400(n=16)$ & $1.81 \pm 0.16$ & $111.61 \pm 10.55$ & $2.24 \pm 0.38$ \\
\hline $600(n=21)$ & $1.94 \pm 0.49$ & $100.28 \pm 7.56$ & $2.62 \pm 0.32$ \\
\hline $800(n=7)$ & $1.74 \pm 0.36$ & $81.96 \pm 9.03$ & $2.90 \pm 0.41$ \\
\hline F-value & 0.47 & 1.64 & 0.61 \\
\hline$p$-value & $>0.05$ & $>0.05$ & $>0.05$ \\
\hline
\end{tabular}

$P>0.05:$ Non-significant difference 
Annals of the College of Medicine, Mosul

Vol. 32 No. 182,2006

Table (3): Comparison of thyroid function tests between males and females in carbamazepine (CBZ) treated group.

\begin{tabular}{|l|c|c|c|}
\hline \multirow{2}{*}{ Parameters } & \multicolumn{2}{|c|}{ Mean $\pm S D$} & p-value \\
\cline { 2 - 4 } & Males $(n=18)$ & Females $(n=26)$ & $>0.05$ \\
\hline$\Pi_{3}(\mathrm{nmol} / \mathrm{L})$ & $1.81 \pm 0.61$ & $1.89 \pm 0.46$ & $>0.05$ \\
\hline$\pi_{6}(\mathrm{nmol} / \mathrm{L})$ & $97.65 \pm 38.44$ & $104.14 \pm 36.27$ & $>0.05$ \\
\hline $\mathrm{TSH}(\mathrm{m} / \mathrm{U} / \mathrm{L})$ & $2.81 \pm 1.39$ & $2.33 \pm 1.43$ & \\
\hline
\end{tabular}

$P>0.05:$ Non-significant difference

Table (4): Comparison of thyroid function tests between control and valproic acid (VPA) treated groups.

\begin{tabular}{|l|c|c|c|c|}
\hline \multirow{2}{*}{ Parameters } & \multicolumn{2}{|c|}{ Mean \pm SD } & z-value & p-value \\
\cline { 2 - 5 } & $\begin{array}{c}\text { Control } \\
(n=47)\end{array}$ & Patients on VPA $(n=19)$ & 1.82 & $>0.05$ \\
\hline$\pi_{3}(\mathrm{nmol} / \mathrm{L})$ & $1.84 \pm 0.44$ & $2.03 \pm 0.32$ & 0.96 & $>0.05$ \\
\hline$T_{4}(\mathrm{nmol} / \mathrm{L})$ & $119.22 \pm 8.07$ & $125.49 \pm 18.22$ & 0.88 & $>0.05$ \\
\hline$T S \mathrm{H}(\mathrm{mlU} / \mathrm{L})$ & $2.24 \pm 0.76$ & $2.10 \pm 1.14$ & \\
\hline
\end{tabular}

$P>0.05:$ Non-significant difference

\section{Results}

The results for serum $\mathrm{TT}_{3}, \mathrm{TT}_{4}$, and $\mathrm{TSH}$ were established in the control group 3. The values were $1.84 \pm 0.44$ (range 1.07-2.76) $\mathrm{nmol} / \mathrm{L}$ for $\mathrm{TT}_{3}, 119.22 \pm 18.07$ (81.94156.05) nmol/L for $\mathrm{TT}_{4}$ and $2.24 \pm 0.76$ (1.01-3.91) $\mathrm{mIU} / \mathrm{L}$ for TSH. No statistically significant difference in all these parameters of TFT was observed between males and females.

The TFT in patients on CBZ monotherapy was compared with that in the control subjects. Mean $\mathrm{TT}_{4}$ concentration was significantly lower in epileptic patients on CBZ (101.49 $\pm 36.87 \mathrm{nmol} / \mathrm{L})$ than in the control group $(119.22 \pm 18.07 \mathrm{nmol} / \mathrm{L})$, $(p<0.01)$. However, mean $\mathrm{TT}_{3}$ and $\mathrm{TSH}$ values were not significantly different from those in the control group, Table 1. No significant effect was observed with regard to the daily $\mathrm{CBZ}$ dose and each of $\mathrm{TT}_{3} \mathrm{TT}_{4}$ and TSH, Table 2. The duration of therapy showed also no significant correlation with $\mathrm{TT}_{3} . \mathrm{TT}_{4}$ and $\mathrm{TSH}$ with $r$ values of -0.04 ,
0.06 and -0.28 respectively. Also, no effect of sex was observed on $\mathrm{TT}_{3}, \mathrm{TT}_{4}$ and $\mathrm{TSH}$, Table 3.

In epileptic patients on VPA as a monotherapy, the mean values of $\mathrm{TT}_{4}, \mathrm{TT}_{3}$ and TSH were not significantly different from those in the control group. Table 4. Also no effect was observed with regard to the daily dose of VPA and $\mathrm{TT}_{3}, \mathrm{TT}_{4}$ and $\mathrm{TSH}$, Table 5. The duration of therapy showed no significant correlations with $\mathrm{TT}_{3}$, $\mathrm{TT}_{4}$ and $\mathrm{TSH}$ with $r$ values of $0.33,-0.02$ and -0.12 respectively. No effect of sex was observed on $\mathrm{TT}_{3}, \mathrm{TT}_{4}$ and TSH, Table 6.

When comparing the different parameters of thyroid function between CBZ and VPA treated groups, only mean $\mathrm{TT}_{4}$ was found to be significantly lower $(P<0.05)$ in the CBZ treated patients $(101.49 \pm 36.87 \mathrm{nmol} / \mathrm{L})$ than in VPA treated patients (125.49 \pm $18.22 \mathrm{nmol} / \mathrm{L})$. However, no statistically significant difference was found in $\mathrm{TT}_{3}$ and TSH in both groups, Table 7 .

Table (5): Effect of valproic acid (VPA) dosage on thyroid function tests.

\begin{tabular}{|l|c|c|c|}
\hline \multicolumn{1}{|c|}{ Dosage (mg/day) } & \multicolumn{3}{|c|}{ Mean \pm SE } \\
\cline { 2 - 4 } & $\pi_{3}(\mathrm{nmol} / \mathrm{L})$ & $\pi_{4}(\mathrm{nmal} / \mathrm{L})$ & TSH (m/U/L) \\
\hline $400(n=5)$ & $1.83 \pm 0.19$ & $141.38 \pm 8.48$ & $1.70 \pm 0.56$ \\
\hline $600(n=11)$ & $2.11 \pm 0.09$ & $121.50 \pm 5.30$ & $2.18 \pm 0.40$ \\
\hline $800(n=3)$ & $2.05 \pm 0.05$ & $113.70 \pm 8.60$ & $2.50 \pm 0.40$ \\
\hline F-value & 1.18 & 2.659 & 0.36 \\
\hline$p$-value & $>0.05$ & $>0.05$ & $>0.05$ \\
\hline
\end{tabular}

$P>0.05$ : Non-significant difference

Table (6): Comparison of thyroid function tests between males and females in valproic acid (VPA) treated group.

\begin{tabular}{|l|c|c|c|}
\hline \multirow{2}{*}{ Parameter } & \multicolumn{2}{|c|}{ Mean $\pm \mathrm{SD}$} & p-value \\
\cline { 2 - 4 } & Males $(\mathrm{n}=9)$ & Females $(\mathrm{n}=10)$ & $>0.05$ \\
\hline$\pi_{3}(\mathrm{nmol} / \mathrm{L})$ & $1.99 \pm 0.27$ & $2.09 \pm 0.39$ & $>0.05$ \\
\hline $\mathrm{TT}_{1}(\mathrm{nmol} / \mathrm{L})$ & $124.78 \pm 20.10$ & $126.41 \pm 17.03$ & $>0.05$ \\
\hline$T \mathrm{SH}(\mathrm{miU} / \mathrm{L})$ & $1.90 \pm 1.14$ & $2.36 \pm 1.17$ & \\
\hline
\end{tabular}

$P>0.05$ : Non-significant difference 
Annals of the College of Medicine, Mosul

Vol. 32 No. 182,2006

Table (7): Comparison of thyroid function tests between carbamazepine (CBZ) and valproic acid (VPA) treated groups.

\begin{tabular}{|c|c|c|c|c|}
\hline \multirow{2}{*}{ Parameter } & \multicolumn{2}{|c|}{ Mean \pm SO } & \multirow{2}{*}{$z$-value } & \multirow{2}{*}{ p-value } \\
\hline & Patients on CBZ $(n=44)$ & Patients on VPA $(n=19)$ & & \\
\hline$\pi_{3}(\mathrm{nmol} / \mathrm{L})$ & $1.86 \pm 052$ & $2.03 \pm 0.32$ & 1.49 & $>0.05$ \\
\hline$\pi_{4}(\mathrm{nmol} / \mathrm{L})$ & $101.49 \pm 36.87$ & $125.49 \pm 18.22$ & 2.57 & $<0.05^{\circ}$ \\
\hline $\mathrm{TSH}(\mathrm{mIU} / \mathrm{L})$ & $2.52 \pm 1.42$ & $2.10 \pm 1.14$ & 0.911 & $>0.05$ \\
\hline
\end{tabular}

* $P<0.05$ : Significant difference

Table (8): Results of other authors regarding the effects of CBZ and VPA on thyroid function tests.

\begin{tabular}{|c|c|c|c|c|}
\hline 1. & CBZ & Caksen et al ${ }^{(1 क)}$ & TT4 and free T4: low & T3 and TSH unaffected \\
\hline 2. & $\mathrm{CBZ}$ & Yuksel et al (IS) & TT4, free T4 and free T3: low & TT3 and TSH : unaffected \\
\hline 3. & $\mathrm{CBZ}$ & Strandjord et al ${ }^{(10)}$ & Tा4, free $T 4$ index and TT3: low & TSH: unaffected \\
\hline 4. & CBZ & Conran et al ${ }^{(24)}$ & TT4: reduced & Free T4, T3 and TSH: unaffected \\
\hline 5. & VPA & Bentsen et al ${ }^{(8)}$ & TT4, free T4 and TT3: reduced & \\
\hline 6. & $\mathrm{CBZ}$ & Verrotti et al ${ }^{(2)}$ & TT4 and Free T4: lower & TT3, free T3 and TSH: unaffected \\
\hline & VPA & & & $\begin{array}{c}\text { TT4, free } \mathrm{T} 4, \mathrm{TT} 3, \text { free } \mathrm{T} 3 \text { and } \mathrm{TSH} \\
\text { unaffected }\end{array}$ \\
\hline 7. & VPA & Eiris-punal et al ${ }^{(10)}$ & $\begin{array}{c}\text { TT4, free T4 and TT } 3: \text { Lower } \\
\text { TSH: higher }\end{array}$ & \\
\hline 8. & VPA & Caksan et al ${ }^{(22)}$ & & TT3, T4 and TSH: unaffected \\
\hline 9. & $\mathrm{CBZ}$ & Vainjonpaa et al ${ }^{(23)}$ & T14 and free T4: reduced & TSH: unaffected \\
\hline & VPA & & TSH : increased & TT4 and free T4: unaffected \\
\hline
\end{tabular}

\section{Discussion}

The present study revealed a reduced mean $\mathrm{TT}_{4}$ levels in patients using $\mathrm{CBZ}$ monotherapy, while $\mathrm{TT}_{3}$ and $\mathrm{TSH}$ levels were not different from the controls. These results agreed with the results of Caksen et al. ${ }^{(14)}$, who evaluated the effects of $C B Z$ as a long term monotherapy on thyroid function in 18 epileptic children, with a duration of 10 months -5 years, They reported that total and free $T_{4}$ levels were significantly lower than in the control group, while $\mathrm{T}_{3}$ and $\mathrm{TSH}$ levels did not differ from the controls, table 8 . Yuksel et al. ${ }^{(15)}$ also noted that after CBZ monotherapy, serum levels of $T T_{4}$, free $T_{4}$ and free $T_{3}$ were found to be low, but serum $\mathrm{TT}_{3}$ and $\mathrm{TSH}$ were unaffected. Strandjord et al. ${ }^{(16)}$ studied the influence of CBZ on serum $T_{4}$ and $T_{3}$ in 42 epileptic patients. He observed that $\mathrm{TT}_{4}$, free $T_{4}$ index and $T_{3}$ were significantly lower than in the controls, while TSH did not differ between patients and controls.

Low serum $\mathrm{TT}_{4}$ with normal $\mathrm{TSH}$ levels are commonly associated with medications ${ }^{(5)}$, such as anticonvuisants, that have been implicated to cause thyroid disorders. It has been known since 1961, that phenytoin has a significant effect on the levels of thyroid hormones ${ }^{(17)}$. In his study, Hansen et al. ${ }^{(18)}$ evaluated the effects of diphenylhydantoin on thyroid function in 26 epileptic patients. His data revealed a decrease in serum $\mathrm{TT}_{4}$, free $\mathrm{T}_{4}$ index and $\mathrm{TT}_{3}$ to $75 \%$ of control values, while TSH was significantly increased. Serum total and free thyroid hormone concentrations were estimated in 42 epileptic patients taking (phenytoin, phenobarbitone and carbamazepine) either alone or in combination. It was found that there was a significant reduction in $\mathrm{TT}_{4}$, free
$T_{4}$ and free $T_{3}$, in the treated group compared with the controls ${ }^{(19,20)}$.

The current study involved also epileptic patients on VPA monotherapy. Serum levels of $\mathrm{TT}_{4}, \mathrm{TT}_{3}$ and $\mathrm{TSH}$ were found to be not different from the controls. Bentsen et al. ${ }^{(8)}$, reported that VPA as a monotherapy causes a reduction in $\mathrm{TT}_{4}$, free $\mathrm{T}_{4}$ and $\mathrm{TT}_{3}$ levels. Verrotti et al. ${ }^{(21)}$ on evaluating the effects of CBZ or VPA in 37 epileptic children reported that $\mathrm{TT}_{4}$ and free $\mathrm{T}_{4}$ levels were significantly lower in patients treated with $\mathrm{CBZ}$ and in those treated with $\mathrm{CBZ}$ plus VPA in comparison with controls. Serum $\mathrm{TT}_{4}$ and free $\mathrm{T}_{4}$ concentrations were unaffected by VPA monotherapy. Serum $\mathrm{TT}_{3}$ and free $\mathrm{T}_{3}$ as well as TSH concentrations were similar in the three groups of studied patients. Eiris-punal et al. (10) recorded lower mean $\mathrm{TT}_{4}$, free $\mathrm{T}_{4}, \mathrm{TT}_{3}$ and higher mean TSH in epileptic children on VPA therapy as compared with controls. Caksan et al. ${ }^{22)}$, in their study, evaluated the effects of chronic VPA therapy on thyroid function in 31 epileptic children, with a duration of therapy of 1-5 years. their finding revealed that mean levels of $T_{3}, T_{4}$ and TSH were not different from the control and they suggested that VPA has no effect on thyroid function in childhood epilepsy. A recent work done by Vainionpaä et al. (23) involving 78 girls on antiepileptic monotherapy, of whom 41 on VPA, 19 on CBZ and 18 on oxcarbazepine (10-keto analogue of $\mathrm{CBZ}$ ) as well 54 healthy agematched controls, studying effects of such antiepileptics on thyroid function. The study indicated that both CBZ and oxcarbazepine reduces $T_{4}$ and free $T_{4}$, despite the fact that $\mathrm{CBZ}$ and oxcarbazapine have different metabolic pathways in the liver (CBZ by 
sxidation and oxcarbazapine by reduction). However, TSH ievels were not different "om the controls. While VPA was associated with a r.armal serum $\mathrm{TT}_{4}$, free $\mathrm{T}_{4}$ and increased TSH levels as compared to the controls. Finding a normal TSH levels in this study is in consistence with the study conducted by Conran et al. (24), who investigated the hypothalamic-pituitary axis (HPA) function in children and adolescents receiving long term monotherapy with either CBZ or VPA. They found a significant reduction in $\mathrm{TT}_{4}$ in the $C B Z$ group, while ree $T_{4}, T_{3}$ and $\mathrm{TSH}$ response to thyrotropin-releasing hormone were similar in both groups. They concluded that HPA function in children and adolescents is not compromised by long-term monotherapy with CBZ or VPA In their study. Thomas et al. (25) found no correlation between neuropsychological impairment among epileptic patients and the levels of thyroid hormones.

Carbamazepine is considered a drug of first choice for the treatment of partial and secondarily generalized seizures ${ }^{(26)}$ Valproate also has been found to be an effective antiepileptic drug in many types of epilepsy (27). Although these two antiepileptic drugs are well tolerated, many effects on endocrine function have been reported in the literatures (28, 29) Carbamazepine is a well-known stimulant of the microsomal enzymes system of the liver-metabolizing thyroid hormones (30), whereas VPA does not seem to have similar enzyme-inducing effect ${ }^{(31)}$. It has been postulated that serum $\mathrm{TT}_{4}$ levels are low in epileptics receiving CBZ because of the accelerated metabolism of thyroid hormones in the liver ${ }^{(32)}$. Furthermore, an increased peripheral conversion of $T_{4}$ to $T_{3}$ during $\mathrm{CBZ}$ therapy also has been suggested as an explanation for the slightly changed or unchanged $T_{3}$ levels ${ }^{(33)}$. Interestingly, Eravci et al. ${ }^{(34)}$, demonstrated that CBZ induces significant changes in $5^{\circ}$ D-ll and $5^{\circ}$ D-lll activities in up to 10 regions of the rat brain; these changes in deiodinase activities, perhaps present in the peripheral tissues as well, could have a role in the explanation of our results. Also, although serum $\mathrm{TT}_{4}$ were reduced, such patients do not require thyroxine supplementation, as it is the level of thyrotropin which is important in thyroid disorders, and its normal level excludes primary involvement of thyroid gland by a disease process ${ }^{(35)} \mathrm{TT}_{4}$ shows an apparent lower level as the dose of carbamazepine increases, this did not show a statistically significant relation probably because of the small number of patients in the subgroups.
De Luca et al. ${ }^{(36)}$, suggesting that hypothyroidism in patients with partial epilepsy to whom CBZ had been administered requires a higher $L-T_{4}$ substitutive regimen. We suggest according to the result of this study that CBZ is a good choice to treat an epileptic patient complaining from hyperthyroidism

in conclusion, in epileptic patients with thyroid disease, probably VPA may be more suitable than $\mathrm{CBZ}$ for the potential influence of the latter on $\mathrm{TT}_{4}$.

\section{References}

1. Smith AF, Beckett GJ, Walker SW, Rae PWH. Lecture Notes on Clinical Biochemistry. $6^{\text {th }}$ ed. London: Blackwell, 1998; pp. 191-198.

2. Supit EJ, Peiris AN. Interpretation of laboratory thyroid function tests for the primary care physician. South Med J 2002; 95 (5) : 481-485

3. Mclver B. Nonthyroid influences on thyroid function. Endocrinol 2001; 3 : 212.

4. Surks MI, Sievert R. Drugs and thyroid function. N Engl J Med 1995; 333(25): 1688-1694

5. Amberson J, Drinka PJ. Medication and low serum thyroxine values in nursing home residents. South Med J 1998: 91(5): 437-440.

6. Porter RJ, Meldrum BS. Antiepileptic drugs. In : Katzung BG. Basic and Clinical Pharmacology. $7^{\text {th }}$ ed.. San Francisco: Appleton and Lange. 1998; pp.386-408.

7. Isojarvi JI, Pakarinen AJ, Myllya W. Thyroid function in epileptic patients treated with carbamazepine. Arch Neurol 1989, 46(11): 1175-1178.

8. Bentsen KD, Gram L, Veje A. Serum thyroid hormone and blood folic acid during monotheraby with carbamazepine or valproate. A controlled study. Acta Neurol Scand 1983; 67(4): 235-241.

9. Tanaka K, Kodama S, Yokoyama S Komatsu $M$, Konishi $H$, Momota $K$ Matsuo $T$. Thyroid function in children with long-term anticonvulsant treatment Pediatr Neurosci 1987; 13(2) : 90-94.

10. Eiris-Punal J, Del Rio-Garma M, Del Rio- Garma MC, Lojo-Rocamonde S, Novo-Rodriguez I, Castro-Gago M. Longterm treatment of children with epilepsy with valproate or carbamazepine may cause subclinical hypothyroidism Epilepsia 1999; 40(12):1761-1766

11. Isojarvi JIT, Laatikainen TJ, Knip M, et al. Obesity and endocrine disorders in women taking valproate for epilepsy. Ann Neurol 1996; 39:579-584

12. Rattya J, Turkka J, Pakarinen AJ, et al. Reproductive endocrine effects of valproate, carbamazepine, and 
oxcarbazepine in men with epilepsy. Neurology 2001; 56:31-36.

13. Kirkwood BR. Essentials of Medical Statistics. $1^{\text {st }}$ ed. Oxford: Blackwell. 1988. pp. 43-56.

14. Caksen $H$, Dülger $H$, Cesur $Y$, Tuncer BO. Evaluation of thyroid and parathyroid functions in children receiving long-term carbamazepine therapy. Intern J Neuroscience 2003; 113: 1213-1217.

15. Yuksel A, Yalcin E, Cenani A. Influence of long-term carbamazepine treatment on thyroid function. Acta Paediatr Jpn 1993; 35(3): 229-232.

16. Strandjord RE, Aanderud S, Myking OL, Johannessen SI. Influence of carbamazepine on serum thyroxine and triiodothyronine in patients with epilepsy. Acta Neurol Scand 1981; 63(2): 111-121.

17. Heyma P, Larkins RG, Perry-Keene D, Peter CT, Ross D, Sloman JG. Thyroid hormone levels and protein binding in patients on long term diphenylhydantoin treatment. Clin Endocrinol 1977; 6(5): 369-376

18. Hansen JM, Skovsted L, Lauridsen UB, Kirkegaard C, Siersbek-Nielsen $K$. The effect of diphenylhydantoin on thyroid function. J Clin Endocrino. Metab 1974; 39: 785-789.

19. Yeo PPB, Bates D, Home JG, Ratcliffe WA, Schardt CW, Heath $A$, Evered DC. Anticonvulsants and thyroid function. $\mathrm{Br}$ Med J 1978; 1: 1581-1583

20. Curran PG, DeGroot LJ. The effect of hepatic enzyme-inducing drugs on thyroid hormones and the thyroid gland. Endocr Rev 1991; 12:135-150.

21. Verrotti A, Basciani F, Morresi $S$, Morgese G, Chiarelli F. Thyroid hormones in epileptic children receiving carbamazepine and valproic acid. Pediatr Neurol 2001; 25: 43-46.

22. Caksen $H$, Dülger $H$, Cesur $Y$, Tuncer BO. No effect of long-term valproate theraby on thyroid and parathyroid functions in children. Intern $J$ Neurosci 2002; $112: 1371-1374$

23. Vainjonpää LK, Mikkonen K, Rättyä J, Knip M, Pakarinen AJ, MyllyłäW, Isojarvi JI. Thyroid function in girls with epilepsy with carbamazepine, oxacarbazepine or valproate monotherabyand after withdrawal of medication. Epilepsia 2004; 45(3): 197-203.

24. Conran MJ, Kearney PJ, Callaghan MN, Murphy D, Goggin T. Hypothalamic pituitary function testing on children receiving carbamazepine or sodium valproate. Epilepsia 1985; 26(6): 585588.

25. Thomas SV, Padmanabhan AV, Sarma PS. Neuropsychological impairment and altered thyroid hormone levels in epilepsy. Natl Med J India 1998; 11:6265

26. Feely $\mathrm{M}$. Drug treatment of epilepsy. $\mathrm{Br}$ Med J 1999; 318: 106-109.

2-. Desilva M, Macardle B, McGowan M, Hughes E, Stewart J, Neville BGR, et al. Randomised comparative monotherapy trial of phenobarbitone, phenytoin, carbamazepine, or sodium valproate for newly diagnosed childhood epilepsy. Lancet 1996; 347: 709-713.

28. Toone BK, Wheeler M, Fenwick PB. Sex hormone changes in male epileptics. Clin Endocrinol 1980; 12 (4): 391-395.

29. Isojarvi Jl, Pakarinen AJ, Ylipalosaari PJ, Myliyla W. Serum hormones in male epileptic patients receiving anticonvulsant medication. Arch Neurol 1990; 47(6): 670-676

30. Eravci $M$, Pinna $G$, Meinhold $H$, Baumgartner A. Effects of pharmacological and non pharmacological treatment on thyroid hormone metabolism and concentrations in rat brain. Endocrinology 2000; 141(3): 1027-1040.

31. Perucca E, Hedges A, Makki KA, Ruprah $M$, Wilson JF, Richens A. A comparative study of the relative enzyme inducing properties of anticonvulsant drugs in epileptic patients. $\mathrm{Br} J$ Clin Pharmacol 1984; 18(3) : 401-410.

32. Connell JM, Rapeport WG, Gordon S, Brodie MJ. Changes in circulating thyroid hormones during short-term hepatic enzyme induction with carbamazepine.Eur $J$ Clin Pharmacol 1984;26(4):453-6

33. Liewendahl $K$, Majuri $H$, Helenius $T$. Thyroid function tests in Pateints on longterm treatment with various anticonvulsant drugs. Clin Endocrinol 1978; 8(3): 185-191

34. Eravci $M$, Pinna $G$ Meinhold $H$ Baumgartner $A$. Effects of pharmacological and non pharmacological treatment on thyroid hormone metabolism and concentrations in rat brain. Endocrinology 2000; 141(3): 1027-1040

35. Tiihonen $\mathrm{M}$, Liewendahl $\mathrm{K}$, Waltimo $\mathrm{O}$, Ojala M, Valimaki M. Thyroid status of patients receiving long-term anticonvulsant therapy assessed by peripheral parameters : a placeboControlled thyroxine therapy trial. Epilepsia 1995; 36 (11): 1118-1125.

36. De Luca F, Arrigo T, Pandullo E, Siracusano MF, Benvenga S, Trimarchi $F$. Changes in thyroid function tests induced by 2 month carbamazepine treatment in L- thyroxine-substituted hypothyroid children. Eur J Pediatr. 1986; $145(1-2): 77-79$ 